\title{
Exploring a model for finding meaning in the changing world of work (Part 2)
}

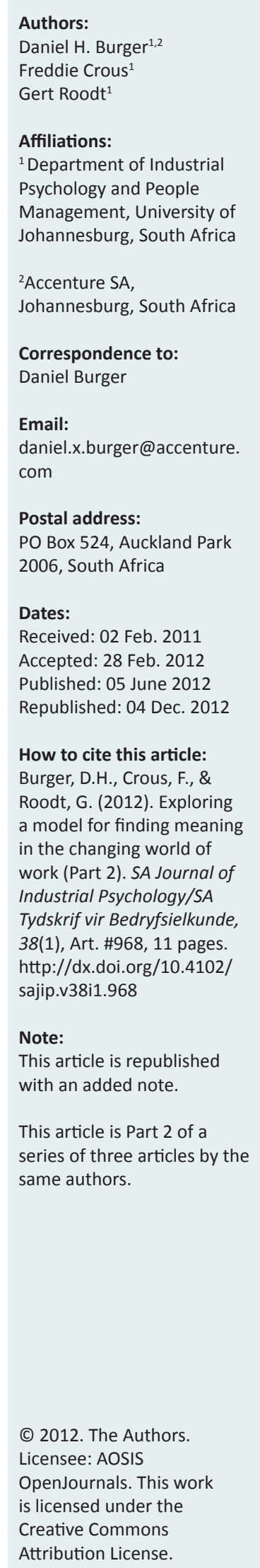

Orientation: This article explores the role that meaning, as logotherapy conceptualises it, can play to facilitate organisational changes.

Research purpose: The purpose of this study is to explore further a model an earlier paper proposed for using employees' experiences of meaning in work contexts to facilitate changes.

Motivation for the study: The researchers could not find a comprehensive model in the literature for addressing employees' experiences of meaning in, or at, work during organisational changes. A previous paper proposed such a model, but it addressed only one component fully. This article seeks to explore this model further to address this apparent gap in the literature.

Research design, approach and method: The researchers used a literature review to conduct the study. The components of the model directed this review in order to find meaning at work.

Main findings: The actions of organisations, which aim to create positive organisational contexts (through practices for improving meaning at work and transcendence) and to frame changes using 'Logo-OD', can improve employees' experiences of meaning during organisational changes.

Practical/managerial implications: Understanding the relationship between meaning and organisational change, and applying the model this article presents, can contribute to the overall success of change initiatives.

Contribution/value-add: This study's primary contribution stems from the novel framework it presents for organisations to use the knowledge about how employees search for meaning to facilitate changes.

\section{Introduction}

The authors offer Burnes' words as a general introduction to this article. Burnes wrote that in a 'fast-moving and unpredictable world, there can be little doubt that organizational change is one of the most important issues facing organizations' (Burnes, 2004, p. 886).

The need to use human capital as a competitive advantage has become a common discourse in the literature (Cascio, 1998; Cook \& Crossman, 2004; Drucker, 2002; Gratton, 2000; McGregor, 1960; O'Reilly \& Pfeffer, 2000; Prahalad \& Hamel, 1990; Richardson \& Vanderberg, 2005; Schuler \& Jackson, 1999; Schuler, Jackson \& Storey, 2001). The contention is that the organisations that succeed in contemporary business environments are those that engage the 'knowledge, experience, skills and energy of their people' (O'Reilly \& Pfeffer, 2000, p. 3). However, employees are the 'organisational resources most difficult to control' (Perez \& De Pablos, 2003, p. 82) because they 'can choose to give or withhold [their] knowledge' (Gratton, 1998, p. 13). According to Gratton (1998), the key to achieving employee co-operation, and a competitive advantage, lies in their search for meaning in or at ${ }^{1}$ work. According to Viktor Frankl's logotherapy (1967, 1978, 1984, 1986, 1988, 2000a, 2000b), meaning plays a crucial role in one's life. He proposed that discovering meaning will significantly improve one's quality of life, irrespective of the circumstances. Logotherapy aims to help one to find meaning, or purpose, in life (Fabry, 1987, 1988; Frankl, 1967, 1984, 1986, 1988, 2000a, 2000b).

Research shows that employees rely increasingly on their work to define their own meaning in life (Bartlett \& Ghoshal, 1994; Heil, Bennis \& Stephens, 2000; Morin, 1995). However, organisational changes often threaten that which may be central to employees' experiences of meaning in or at work (Abel \& Sementelli, 2005). These threats often result in resistance to change (Antonacopoulou \& Gabriel, 2001; Frances, 1995). Burger, Crous and Roodt (2008) showed that employees' search for meaning could play a critical role in organisations' ability to manage changes. Based on the principles of logotherapy, they argued that organisations can reduce change resistance through

1.This article explains the difference between 'meaning in' and 'meaning at' work later. 
interventions - known as 'Logo-OD' - that will address employees' experiences of meaning. Burger et al. (2008) also suggested a model for directing meaning-based interventions to facilitate organisational changes.

\section{Purpose of the study}

This article seeks to explore further the model that Burger et al. (2008) presented. This model, which the section that follows discusses, suggests that organisations can use Logo-OD as positive trigger events to facilitate organisational changes, to assist with developing positive organisational contexts and to frame organisational changes. It can increase the readiness to change of employees and facilitate organisational changes more effectively. The researchers could find no such application of logotherapy in the literature. It suggests wide scope for exploring this area of study.

The researchers will achieve this by presenting a brief overview of the model and its associated theoretical constructs. The problem statement, research objectives and motivation for the study, all of which relate to the further exploration of this model, follow. The researchers then discuss the research design and present a literature review that explores the concepts of positive organisational contexts and framing changes using Logo-OD.

\section{Current theoretical perspectives Logo-OD}

Burger (2007) used the term 'Logo-OD' to describe the application of logotherapy as an organisation development (OD) intervention. Burger argued that a logotherapeutic intervention could decrease change-restraining forces (resistance to change) and increase change-driving forces (readiness for change).

The classic change model of Lewin (1951) showed that addressing these forces is essential to facilitate organisational changes successfully. Burger also argued that Logo-OD in isolation would not bring about the shift in attitudes that organisations need to reduce resistance to change. Instead, Burger proposed that these interventions would act as positive trigger events to facilitate organisational changes.

\section{Logo-OD as positive trigger events to facilitate organisational changes}

Avolio and Luthans (2006), as well as Luthans and Avolio (2003), used the concept of trigger events to describe critical incidents - planned or unplanned - that cause people to realise that they need specific courses of action or changes in behaviour to address particular situations.

Burger (2007) argued that applying Logo-OD as positive trigger events can cause employees to find meaning during, or because of, organisational changes. Therefore, it plays a critical role in addressing the causes behind resistance to change. Consequently, Logo-OD helps to facilitate organisational changes. Figure 1 presents an adapted version of the model of Luthans and Avolio (2003) for Authentic Leadership Development (ALD) to explain how this article will apply the concept of Logo-OD.

\section{Empirical findings}

Consistent with their original propositions, Burger et al. (2008) found that a singular application of Logo-OD did not bring about significant changes in participants' experiences of meaning. Nevertheless, these authors reported a positive relationship between the dimensions of meaning and resistance to change. Together with marked patterns in their results ${ }^{2}$, they provided credence to the possible role Logo-OD could play in facilitating organisational changes. However, Burger et al. (2008) emphasised that:

Logo-OD is not proposed to be a panacea in addressing resistance to change. Rather, it is positioned as a positive trigger event for organisational change. For optimal effectiveness, LogoOD must be accompanied by interventions to create a positive organisational context, as well as efforts to frame change initiatives based on the principles underlying logotherapy. (p.39)

As a recommendation for creating positive organisational contexts and for framing changes using logotherapeutic principles, Burger et al. (2008) offered the framework of Pratt and Ashforth (2003) for organisational practices that promote

2.Post-test scores were higher than pre-test scores for the experimental group on all dimensions of the dependent variable in $t$-tests the researchers conducted for related samples and higher on 8 of the 12 dimensions on $t$-tests for independent samples. However, these differences were not statistically significant. The finding is samples. However, these difference finding is bring about sustainable changes in employee attitudes to organisational changes.

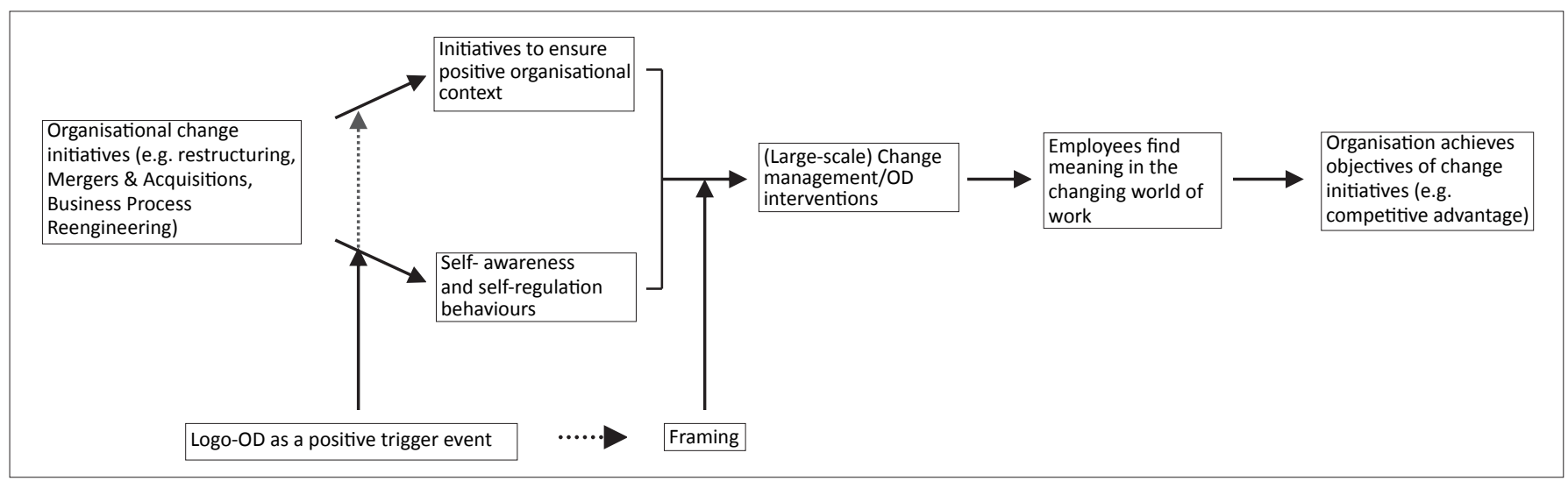

FIGURE 1: A framework for using meaning to facilitate organisational changes. 
meaningfulness (Figure 2) and logotherapeutic concepts that might help to frame changes (Table 1), respectively. By focusing on these frameworks for the rest of the article, Burger attempted to devise a theoretical model for using meaning at work to drive organisational changes.

\section{Problem statement and research objectives}

Helping employees to find meaning in or at work can play significant roles in facilitating organisational changes. LogoOD interventions may be invaluable as positive trigger events. However, organisations need more than this if the changes are to be sustainable because:

given the complexity of organisational change, the difficulty inherent in changing employees' attitudes towards it, and the unlikelihood of a single intervention bringing about a significant change in individuals' experience of meaning. (Burger et al., 2008, p. 39)

Consequently, the section that follows captures the problem statement that is central to this article.

\section{How can organisations use meaning to facilitate organisational changes?}

Burger et al. (2008) explored the role of Logo-OD as positive trigger events. Therefore, this article will focus on two research objectives:

- to investigate the possible role of positive organisational contexts to facilitate employees' experiences of meaning in or at work

- to investigate the possible role of framing changes using Logo-OD principles to facilitate employees' experiences of meaning in or at work.

\section{Rationale for, or value of, the study}

Despite a substantial increase in literature that emphasises how important it is that employees find meaning in or at work, the researchers could find no comprehensive and empirically verified model in the literature for assisting employees to find this meaning. It is a significant gap in the knowledge about the effective facilitation of organisational changes.

The model that Burger et al. (2008) presented is a first step toward constructing such a model. However, because this framework is new, there has only been research into one of its three central components: positive trigger events. Therefore, the rationale for the current study is to explore this model further in order to yield additional knowledge about the role that meaning can play to assist organisations in their change efforts. This knowledge can also serve as the foundation for empirical research into the applicability of the two remaining components: creating positive organisational contexts and framing using logotherapeutic principles to help employees to find meaning in the changing world of work.

\section{Research design Research approach}

The arguments this article presents mainly follow the logotherapeutic school of thought, primarily because of the authority that this theoretical perspective enjoys in its description of, and research into, meaning in life Viktor Frankl, an Austrian psychiatrist-neurologist and holocaust survivor, developed logotherapy. His work is widely known and has been published in more than 23 languages (Havenga Coetzer, 1997; Washburn, 1998). The logotherapeutic outlook on meaning in life extends into the world of work in general and organisational change in particular. Therefore, the key concepts of logotherapy also yielded an evaluation framework used to build key arguments.

\section{Research method}

Given the aims of this article, the researchers chose a literature review as their research strategy. It allowed them to explore the model of Burger et al. (2008) further and to construct a theoretical foundation for conducting empirical research into how one can apply this model to finding meaning in or at work.

Literature reviews are very useful for facilitating knowledge of the area under study and for identifying the significance of work already conducted in the field. According to Hart (2005), they give an insight into how the subject developed and became established. Furthermore, Saunders, Lewis and Thornhill (2007) pointed out that literature reviews facilitate the identification and refining of research ideas that researchers may have overlooked in earlier research.

TABLE 1: Framing changes using the principles that underlie Logo-OD.

\begin{tabular}{ll}
\hline Principle & Application to framing \\
\hline The will to meaning & $\begin{array}{l}\text { Because the 'will to meaning' is the primary motivation behind human existence, organisations should frame their organisational change initiatives so } \\
\text { that employees believe that the initiatives will contribute to their search for meaning. This will motivate employees to support the changes through } \\
\text { their readiness for change behaviours. }\end{array}$ \\
Values & $\begin{array}{l}\text { Employees should believe that change initiatives would help them to express creativity and innovation in their jobs (creative values }{ }^{1} \text { ) as well as to } \\
\text { experience fulfilling relationships and a sense of community (experiential values }{ }^{2} \text { ). Although the reliance on attitudinal values to promote changes } \\
\text { whilst organisations do not address unfavourable circumstances is exploitation, these values may be crucial when organisations place severe strain on } \\
\text { employees' coping resources and undermine their creative and experiential values. }\end{array}$ \\
Self-transcendence & $\begin{array}{l}\text { Employees could - in the right circumstances - place the goals of their organisations before their own and find meaning in them. These circumstances } \\
\text { may include thinking that the changes will contribute to the needs of others or of society (Kets de Vries, 2001; Milliman, Ferguson, Trickett \& Condemi, } \\
\text { 1999). Transformational leadership and inspiring visions or organisational values may play crucial roles here (Burger \& Crous, 2002). }\end{array}$ \\
Noö-dynamics & $\begin{array}{l}\text { Consistent with Lewin's (1951) change model, framing will motivate employees if it clearly shows that past successes ('the meaning that has been found') } \\
\text { are insufficient for sustained performance and that organisations need to change if they are to ensure that their employees realise their potential ('the } \\
\text { meaning to be fulfilled'). }\end{array}$ \\
The existential vacuum & $\begin{array}{l}\text { Employees 'generally do not support change unless compelling reasons convince them to do so... People's readiness for change depends on creating } \\
\text { a felt need for change' (Cummings \& Worley, 2001, p.156). Using framing to illustrate the outcomes of not changing may communicate the need for } \\
\text { change - like depicting (unchanged) organisations as those that are failing and unable to give employees a sense of identity, community and, ultimately, } \\
\text { meaning. }\end{array}$
\end{tabular}




\section{Targeted body of literature}

The researchers conducted data searches of all portals available to the University of Johannesburg. They included searches of online scholarly journals using engines like EbscoHost, Infotrac and Emerald. The researchers searched a wide range of publications to ensure that adequate data supported the conclusions they drew. They used local and international literature as far as they could. The researchers sourced information by focusing on the components of the Pratt and Ashforth (2003) model and critical concepts in framing. With regard to the former, the focus of the search was on literature that addressed - either directly or indirectly -the implications of each of the components of the model.

Based on the tenets of logotherapy, the researchers adopted an evaluative stance to determine whether these components can contribute to meaning in life. Finally, with regard to framing, they used literature from both the cognitive and postmodern frameworks to explore the implications of language - again against frameworks that logotherapy suggests.

\section{Gathering the data}

The researchers gathered their data specifically to meet the objectives of this paper. Key words contained in this article were the instruments for gathering the data. These key phrases included, firstly, generic phrases like 'meaning in work' and 'meaning at work'. Secondly, in terms of positive organisational contexts, they investigated each of the components of the model of Pratt and Ashforth (2003) independently. In other words, they used each of these components as key words to gather literature. Finally, with regard to framing, they focused their data collection on the use of this construct to manage changes. Therefore, they used phrases like 'framing and organisational change'.

As the researchers noted earlier, they examined literature from both the cognitive psychological and constructionist approaches to framing. Their keywords yielded a vast amount of literature. Initially, the researchers refined their searches by including filters like 'Frankl' and 'logotherapy' to determine whether other researchers have explored similar concepts. In addition, they used search filters like 'meaning', 'meaning in life' and 'meaning in or at work' to reduce the vastness of the literature that is relevant to the more popular components of the model of Pratt and Ashforth (2003), like transformational leadership and organisational culture.

The researchers then evaluated the body of literature for inclusion in this article. They evaluated it against the tenets and general principles of logotherapy. In addition, they scrutinised the research articles in terms of the relevance of their content to Frankl's work and the objectives of this paper. They evaluated both supportive and contrary arguments. As a final step, the researchers synthesised the data to present a comprehensive argument for applying the concepts of positive organisational contexts and framing to managing organisational change.

\section{Analysis of the data}

Consistent with their approach for collecting data, the researchers analysed their data in terms of the value that the various themes they identified may add in helping employees to find meaning. The researchers evaluated the data they gathered for the model of Pratt and Ashforth (2003) against logotherapeutic principles to determine how much each of its components could help employees to find meaning. In their analysis of the data relevant to framing, the researchers focused on the extent to which the data conformed to Frankl's conceptualisation of meaning and, in particular, how framing can contribute to the search for meaning. Therefore, this analysis facilitated the construction of a solid conceptual base for future empirical research into the various components the researchers investigated, with particular emphasis on the role that each can play in helping employees to find meaning in or at work and in helping organisations to facilitate organisational changes successfully.

\section{Presentation of the data}

The researchers present the data in two sections. Firstly, the researchers used the model of Pratt and Ashforth (2003) to guide discussion about how positive organisational contexts can help employees to find meaning in or at work. They used the logotherapeutic conceptualisation of meaning throughout. They evaluated each component of the model separately. Secondly, the researchers explored the concept of framing in terms of its importance in managing changes and the usefulness of Logo-OD principles to applying framing practices.

\section{Results \\ Organisational practices to address meaning in and at work: creating positive organisational contexts}

Figure 2 offers the model of Pratt and Ashforth (2003) for organisational practices that promote meaningfulness as a framework for creating positive organisational contexts. The section that follows explores the model briefly to illustrate the role that each component might play in employees' search for meaning.

\section{Recruitment, selection and socialisation}

Organisations' recruitment, selection and socialisation processes are at the core of the model. These practices have a significant effect on the extent to which employees experience a job-person or person-organisation fit. Recruitment and selection processes identify whether employees will 'fit' into organisations and their cultures (Byars \& Rue, 2000; Schein, 1994), particularly when values are discussed early in the recruitment process to determine whether employees' values align with those of their organisations (Green, 2007). Socialisation practices, in turn, aim at improving this fit (Pratt \& Ashforth, 2003) by 'transmitting key elements of an organization's culture to its employees ... [to shape] the 


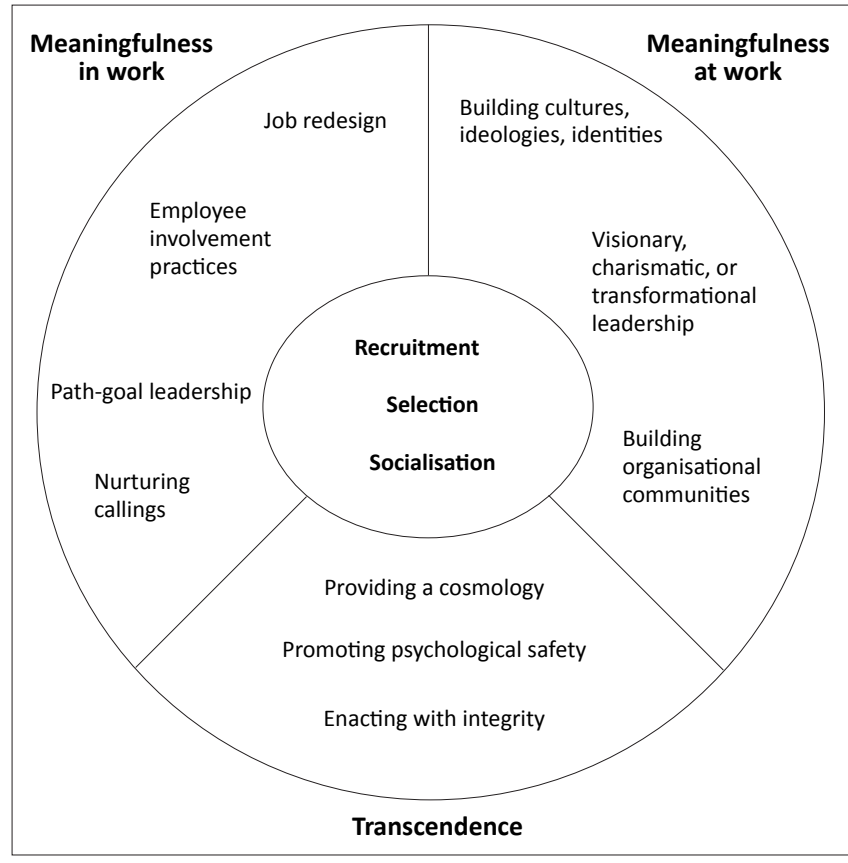

FIGURE 2: Organisational practices that promote meaningfulness (adapted from Pratt \& Ashforth, 2003, p. 316).

attitudes, thoughts, and behaviors of employees' (Newstrom \& Davis, 1997, p. 107). Such a fit promotes the expression of one's identity through one's work and helps employees to find meaning in their organisations and their jobs. In logotherapeutic terms, a job-person or person-organisation fit will create contexts in which employees will engage more comfortably and easily in creative and experiential values, thereby helping them to find meaning in or at work.

\section{Meaningfulness in work}

Pratt and Ashforth (2003) argued that finding meaning in work links to the roles that employees play - or 'in what one does' (p. 314). The first practice they suggested could help to promote meaning at work is 'building cultures' that may encapsulate 'comprehensive ideologies' and 'collective level identities' (Pratt \& Ashforth, 2003, p. 318; emphasis in original). Organisational cultures encompass shared systems of meaning that - as with ideologies - prescribe the assumptions, beliefs, values and norms that the members of the organisations hold (Newstrom \& Davis, 1997).

Burger (2007) showed that the cultures of organisations could have significant effects on how employees find meaning in them. Kurashina (2005) pointed out that organisational cultures involve shared values and norms through which employees derive meaning, whilst Strandgaard Pedersen and Dobbin (2006, p. 899) emphasised the notion of organisational cultures that provide shared or 'collective meaning'. Organisational identities encapsulate specific standards for employees' behaviour (Kurashina, 2005) and link strongly to - yet remain distinct from - organisations' values $^{3}$ and cultures (Corley, Harquail, Pratt, Glynn, Fiol \& Hatch, 2006).

3.Aust (2004) cited research that shows that organisations establish their identities by communicating their values.
This construct poses a potential threat to organisational changes because employees more readily accept changes that they see 'as enhancing organizational identity' (Chreim, 2006, p. 315). In addition, Corley et al. (2006) posited that organisational identity-related issues 'engage profound and fundamental questions about meaning and being' (p. 96), which indicate the importance of this construct in assisting employees to find meaning at work.

Organisational communities emerge through practices that promote employees' sense of belonging in organisations (Pratt \& Ashforth, 2003). Workplaces often provide 'the most important sense of community' that people experience (Warren, 1996, p. 43) because of a lack of sense of community and the associated isolation one finds in contemporary society (Markow \& Klenke, 2005). Therefore, promoting organisational communities may be crucial if employees are to find meaning in their jobs. According to Pratt and Ashforth (2003), organisations can promote these communities through practices that emulate 'family-like dynamics at work' and supporting missions ${ }^{4}$ that focus on values that go beyond organisational survival to give employees something to believe in (p. 318).

The construct of values is crucial to the concept of organisational communities and aligns with the notion of cultures, ideologies and identities. A significant amount of management literature has pointed out that organisational success requires the acknowledgement that values 'are of equal or greater importance than the traditional economic concepts like efficiency or return on investment' (Dolan \& Garcia, 2002, p. 103). For example, Collins and Porras (1994) reported, in their 'Built to Last', that the 'visionary companies' they studied attributed their success to their systems of core values. In addition, O'Reilly and Pfeffer (2000) presented case studies of a number of high-performing companies, each famous for its strong values and sense of purpose. Finally, Peters and Waterman (1982) reported that:

every excellent company we studied is clear on what it stands for, and takes the process of value shaping seriously. In fact, we wonder whether it is possible to be an excellent company without clarity on values and without having the right sorts of values. (p. 280)

Organisational values also link inextricably to Pratt and Ashforth's (2003) final component of promoting meaning in work: 'visionary', charismatic, or transformational leadership ${ }^{6 \prime}$. McDonald and Gandz (in Aust, 2004, p. 520) stated that 'leaders are fundamentally responsible for determining the values an organization embraces'. Leadership is crucial 'to help people understand why what they are doing is important and makes a difference' (O'Reilly \& Pfeffer, 2000, p. 14) - or, in the context of this article,

4.Burger and Crous (2002) showed that mission statements could play significant roles in helping employees to find meaning in organisations and help them to achieve their goals despite the difficulties associated with organisational changes.

5.According to Pratt and Ashforth (2003), 'visionary leadership' is a synonym for 'transformational leadership'. Therefore, this article will not discuss this concept separately.

6.One can add the concept of 'authentic leadership' to this list, especially because it has a significant effect on organisations' principles and values (Avolio \& Luthans, 2006, p. 195) 
'managing meaning in organizations is of central importance to leaders' (Smircich \& Morgan, in Bean \& Hamilton, 2006, p. 322).

'Charismatic leadership' relates to the emergence of more collectivistic values and a greater sense of community amongst employees. This affects the cultures of organisations (Xenikou \& Simosi, 2006) and employees who see their leaders as 'an expression of themselves and thus intrinsically motivating and meaningful' (Markow \& Klenke, 2005, p. 10). 'Transformational leadership', in turn, is associated with the motivation and inspiration of followers because it gives meaning to their work (Bass, 1985; Boerner, Eisenbeiss \& Griesser, 2007) by tapping 'into deep levels of personal meaning' (Markow \& Klenke, 2005, p. 10) and by focusing on 'the higher needs of employees' (Green, 2007, p. 23).

Despite these propositions, Csikszentmihalyi (2003) showed that very few leaders engage in purposeful actions to ensure that employees experience this meaningfulness. One way in which organisations can promote a sense of meaning is by creating visions 'wherein organizational members experience a sense of calling in that their life has meaning and makes a difference' (Fry in Markow \& Klenke, 2005, p. 10). Pratt and Ashforth (2003) argued that visions are crucial because 'like cultures, ideologies, and collective identities' they 'make membership within a particular organization special, enriching, and meaningful' (p. 318). From a logotherapeutic perspective, Burger and Crous (2002) showed that wellcrafted visions may, in line with Frankl's (1984) concept of noö-dynamics, challenge employees with the potential meaning they have to fulfil, thereby creating tension in organisations to inspire employees to achieve their own and their organisations' growth.

\section{Meaningfulness at work}

Meaningfulness at work involves a sense of belonging: 'Finding meaning in whom one surrounds oneself with as part of organisational membership, and/or in the goals, values, and beliefs that the organisation espouses' (Pratt \& Ashforth, 2003, p. 314). Organisations can promote meaning in work through practices like redesigning jobs, employee involvement practices, path-goal leadership and nurturing callings.

Consistent with Hackman and Oldham's (1980) classic job satisfaction model, Varoglu and Eser (2006, p. 30) contended that redesigning jobs can help to improve the 'perceived meaningfulness of work for the employees'. Similarly, Pratt and Ashforth (2003) maintained that these practices could help employees to find meaning in work when they:

allow members to more fully engage who they are in what they do by increasing the variety of skills used on the job, allowing members to complete a whole and identifiable piece of work ${ }^{7}$, providing autonomy over what to do and when, and offering feedback to facilitate learning. (p. 320)

7.As opposed to the fragmentation of tasks associated with alienation (Haralambos \& Holborn, 1995)
Lawler, Mohrman and Benson (in Pratt \& Ashforth, 2003) argued that organisations can facilitate employee meaning through 'employee involvement' practices because these 'may effectively empower individuals by sharing information, developing knowledge, rewarding skill acquisition, inviting participation, and so forth' (p. 320). This is particularly clear when one considers surveys that show that large numbers of employees are 'disengaged or marginally disengaged' (Buhler, 2007, p. 18) and do not 'feel inspired by their organisation to do their best work or that senior managers are interested in them' (Towers Perrin Global Workforce Study, 2005, p. 4).

Path-goal leadership is a contingency theory of leadership (Yun, Cox \& Sims, 2006) that 'focused on follower satisfaction as the primary indicator of [leaders'] effectiveness' (Hopkins, O'Neil \& Bilimoria, 2006, p. 251). This theory proposes that the role of leaders is to create work environments conducive to helping employees to achieve their organisations' goals (Newstrom \& Davis, 1997). This will help employees' to find meaning in work, firstly by establishing the connection between their inputs and performance and secondly, by removing possible barriers that may undermine the meaning that one finds in work (Pratt \& Ashforth, 2003).

Finally, organisations can improve employees' experiences of meaning in work if employees experience their jobs as a 'calling' (Pratt \& Ashforth, 2003). The traditional notion of a calling relates to religiously inspired work that serves others. However, modern conceptualisations describe a calling as work that adds meaning and purpose to one's life. Therefore, it results in 'deep connections and thus commitments to one's work' (Markow \& Klenke, 2005, pp. 12-13). Employees with calling orientations find meaning in the fulfilment that doing the work itself brings. They experience work as 'a wholly enriching and meaningful activity' (Wrzesniewski, 2003, p. 302).

\section{Transcendence}

The model of Pratt and Ashforth (2003) presupposed that organisations promote meaningfulness at work by focusing on how employees build on their membership(s) in organisations. However, employees' roles largely dictate the extent to which they experience meaning in work. Should organisations succeed in promoting meaning in work and at work, employees may begin to experience transcendence. In logotherapy, this construct is critical to finding meaning in life (Frankl, 1984; 1986). Pratt and Ashforth (2003) argued that transcendence involves:

(1) a connection to something greater than oneself, such as a cause or other people (i.e. transcendence of self through attachment), (2) an integration of the various aspects of oneself, such as identities and traits, into a roughly coherent system (i.e., transcendence of fragmentation through holism and harmony), and (3) self-development, a realization of one's aspirations and potential (i.e., transcendence of the status quo and of limits through growth). (p. 322)

Transcendence results when organisations provide:

strong linkages between who we are, what we do, and why we are here in this context, whilst simultaneously connecting 
workers to something greater than themselves, their tasks, or perhaps even the organization where they work. (Pratt \& Ashworth, 2003, p. 322)

Pratt and Ashforth (2003) maintained that finding meaning at and in work ultimately results in employees experiencing transcendence. In addition, organisations can cultivate transcendence using three organisational practices. These are providing a cosmology, promoting psychological safety and acting with integrity (see Figure 2). One uses the term 'cosmology' most often in the natural sciences and physics when studying the universe or cosmos (Fornaciari \& Dean, 2002). Pratt and Ashforth (2003, p. 323) used the term to describe a comprehensive system of meaning that goes beyond concepts like an organisation's vision or sense of community and 'connects and explains' one's identity, membership, values, purpose and transcendence. These belief systems promote transcendence by providing employees with direction and a place in a 'more ordered picture of the universe' (Weick in Pratt \& Ashforth, 2003, p. 323) Schein (1994; 1996) argued that, during organisational changes, organisations must create a state of 'psychological safety' to prevent threats to employees' identity and integrity. It also prevents the resistance that results. In addition, Pratt and Ashforth (2003) argued that safety is crucial for one to 'leave one's old self-configuration for a new and uncertain one' ( $p$. 323) to experience transcendence. Creating psychological safety is a central characteristic of transformational leaders (Alimo-Metcalfe \& Alban-Metcalfe, 2006). Ideally, opportunity and the resources to engage in creative work must accompany this safety.

Finally, Pratt and Ashforth (2003) stated that organisations can only foster cosmologies, psychological safety and, ultimately, transcendence effectively if they and their leaders act with 'integrity'. Employees must 'perceive congruence between leaders' words and deeds' (p. 324) and must believe that their organisations will promote their personal growth - and not just the growth of their organisations. Leadership integrity is also associated with factors like openness to changes and a sense of 'deep commitment to a mission' (Gardner, 2004, p. 111). Folger and Scarlicki (1999) warned of the importance of the sincerity of leaders by stating that:

employees see right through the manipulative attempts to apply fair, humane, and sensitive treatment - conduct that vouchsafes each person's dignity, treating no one merely as means but always as ends also - as a mere ruse for disguising ulterior motives. (p. 46)

This may be a significant challenge for contemporary organisations. Recent studies have shown that 'only $28 \%$ of today's workforce believe that their senior management has a sincere interest in the satisfaction and well-being of employees' (Towers Perrin Global Workforce Study, 2005, p. 8 ) and that only $39 \%$ of employees 'trust senior management' (Gostick \& Telford, 2006, p. 35).

\section{Giving meaning to organisational changes and development initiatives through framing}

Organisational change is an interpretative process. People act on their interpretations of the world. Therefore, their understandings must change if their actions are to change substantively (Davidson, 2006, pp. 23-24). According to Armenakis, Harris \& Mossholder 'at its core, creating readiness for change involves changing individual cognitions in a set of employees' (1993, p. 283). Bringing about shifts in employees' reactions to changes require organisations to address how employees interpret or make sense of the changes. This section will address the notion of framing as a potential avenue for helping employees to interpret organisational changes in a way that helps them to find meaning in their organisations.

\section{Conceptualising framing}

Chreim (2006) maintained that 'framing plays a major role in change responses' (p. 316) to the extent that it affects 'acceptance of, or resistance to change' (p. 317). Framing denotes the process whereby organisations and their leaders manage meaning 8 in organisations. They do this by 'selecting and highlighting certain facts or issues over others' (Bean \& Hamilton, 2006, p. 324), thereby establishing the frames or boundaries 'within which a person can make sense of a particular phenomenon' (Weick in Bean \& Hamilton, 2006, p. 324). Two perspectives relevant to framing organisational changes are particularly prominent in the literature. The first is that employees make meaning of changes through 'cognitive interpretation' (Bean \& Hamilton, 2006; Bartunek, Rousseau, Rudolph \& DePalma, 2006). This perspective proposes that employees generally engage in attempts to make meaning of change events by gathering and processing information cognitively. Through framing, organisations can create new systems of shared meaning that dictate which behaviours they require, thereby providing the foundation for mobilising employees towards the goals of the organisations that motivate the organisational change initiatives (Scroggins, 2006).

The second perspective emphasises forming frames (or perspectives) through changes in the 'language' that organisations ${ }^{9}$ use. Rosenthal and Peccei (2006) maintained that organisational changes are more effective when a shift in language occurs to the extent that it becomes 'embedded in wider transformations of structure, practices and the physical environment' (p. 67). Such shifts in language are critical for bringing about changes in 'entrenched practices, attitudes and values' (p. 68) because language is a critical 'system for making meaning' that organisations use 'to represent and to construct particular ways of perceiving and thinking about experiences in the workplace' (Ayers, 2005,

8 . One needs to make a distinction between the concept of meaning, which denotes how people make sense of phenomena by interpreting them, and the concept of meaning that is the core of this study.

9.Particularly the language that leaders use. 
p. 5). Therefore, organisations need to change the language they use to describe changes if employees are to find meaning in the change initiatives.

\section{Framing during organisational changes}

According to Scroggins (2006), framing is particularly important in large-scale organisational changes, where fundamental changes are required in the way that employees 'perceive, think, and behave', ultimately resulting in altered 'shared systems of meaning and frameworks of understanding' that are needed to 'create the desired culture, beliefs, values and behaviors' ${ }^{10}$ (p. 84). In these situations, employees:

often gauge organizational change in terms of their own perceived or anticipated gains or losses from it, the extent to which change makes the quality of some aspect of their work or work life better or not (Bartunek et al., 2006, p. 188).

Therefore, the framing should be such that employees will see that organisational changes have beneficial results rather than presenting risks to the things in which they find meaning - particularly as the latter may result in resistance to the changes. Gardner (2004) emphasised that 'resistance' may hamper change efforts - 'strong views and perspectives that are resistant to change' (pp. 17-18). Related to this, Bean and Hamilton (2006) argued that resistance may work against framing attempts because making sense may be 'linked to identity-maintenance, a process rife with tensions associated with insecurities and driven by previously formed attachments to stories, events, and symbols used for ascribing meaning' (p. 327). According to Gardner (2004), employees' minds change when they:

accept the changes that will happen anyway, acknowledge that certain other changes may be impossible, and concentrate one's efforts on those changes of mind that are important, won't occur naturally, but can be achieved with sufficient effort and motivation. (p. 209)

Therefore, a crucial element of ensuring that employees align with the frames organisations present is effective communication. Ideally, organisations need to communicate their change agendas clearly to ensure that all employees have a thorough understanding of the changes. They also need a clear understanding what the changes mean for them because employees typically create:

meaningfulness by understanding where he/she belongs in the organisation and what role he/she fulfils, to truly understand who he/she is within the organisational context and ultimately why the work is meaningful. (Schlecter \& Engelbrecht, 2006, p. 11)

In addition, organisations should construct their communications around visions that are powerful enough to create new organisational schemas. Organisations should also base them on the changes in language they require to frame their changes meaningfully.

\section{Framing organisational changes based on Logo-OD}

Logo-OD could be positive trigger events for organisational changes. Its underlying principles may also affect the extent to

10.Given the role that one assumes these factors play in creating positive organisationa contexts, it is clear that the relationship between framing and the extent to which employees find meaning in their organisations is complex and multidirectional. which organisations are able to create positive organisational contexts and frame organisational change initiatives in ways that will reduce resistance to change. Therefore, Logo-OD principles may be central to forming new employee and organisational schemas and to determining the language organisations should use to express their change initiatives. Burger et al. (2008) argued that five logotherapeutic concepts in particular could be useful here. They are the will to meaning, values, self-transcendence, noö-dynamics and the existential vacuum. Table 1 summarised these concepts, together with the potential usefulness of each for framing changes.Given the purpose of framing in the context of this study, which is to reduce resistance to change, organisations may benefit from directing such framing in accordance with established models of organisational change. In other words, the principles underlying Logo-OD should influence the way that organisations approach changes to schemas and the language that is relevant to the particular aspects of organisations that could be epicentres of resistance to change.

One framework that may be useful here is the Burke-Litwin Organisational Performance and Change model ${ }^{11}$. It consists of 12 categories divided into two groups: transformational and transactional variables (French \& Bell, 1999). Whereas the transformational variables encapsulate the forces where changes may 'require entirely new sets of behaviour', transactional variables 'are influenced by short-term interchange between individuals and groups' (Kinnear \& Roodt, 1998, p. 46). Table 2 presents the fundamental components of this model, together with examples of how organisations can use framing to address each of these to help employees to find meaning in their organisations and, ultimately, to show readiness for change.

\section{Discussion}

The objective of this study was to explore a model for using employees' experiences of meaning in their work contexts to facilitate changes further. This model proposes that using the principles of Logo-OD will lead to interventions that will:

- act as trigger events for organisational changes

- create positive organisational contexts

- frame changes that will help to reduce resistance to organisational change.

In an earlier article, Burger et al. (2008) verified empirically the role that Logo-OD can play as positive trigger events for changes. Consequently, this article focused on exploring the remaining two meaning-based components - creating positive organisational contexts and Logo-OD based framing - through a literature review. Therefore, the importance and primary contribution of this study stems from the novel framework it presents for using the knowledge of how employees search for meaning during changes. Although researchers have written much about the role of meaning in work, the researchers could find no suitable framework in the literature.

11.This model is the foundation of the Change Readiness Inventory (CRI), the instrument that Burger et al. (2008) used to operationalise the resistance to change-readiness for change dimension. 
TABLE 2: The Burke-Litwin Model as a framework for framing organisational changes, using the principles underlying Logo-OD, to reduce resistance to change.

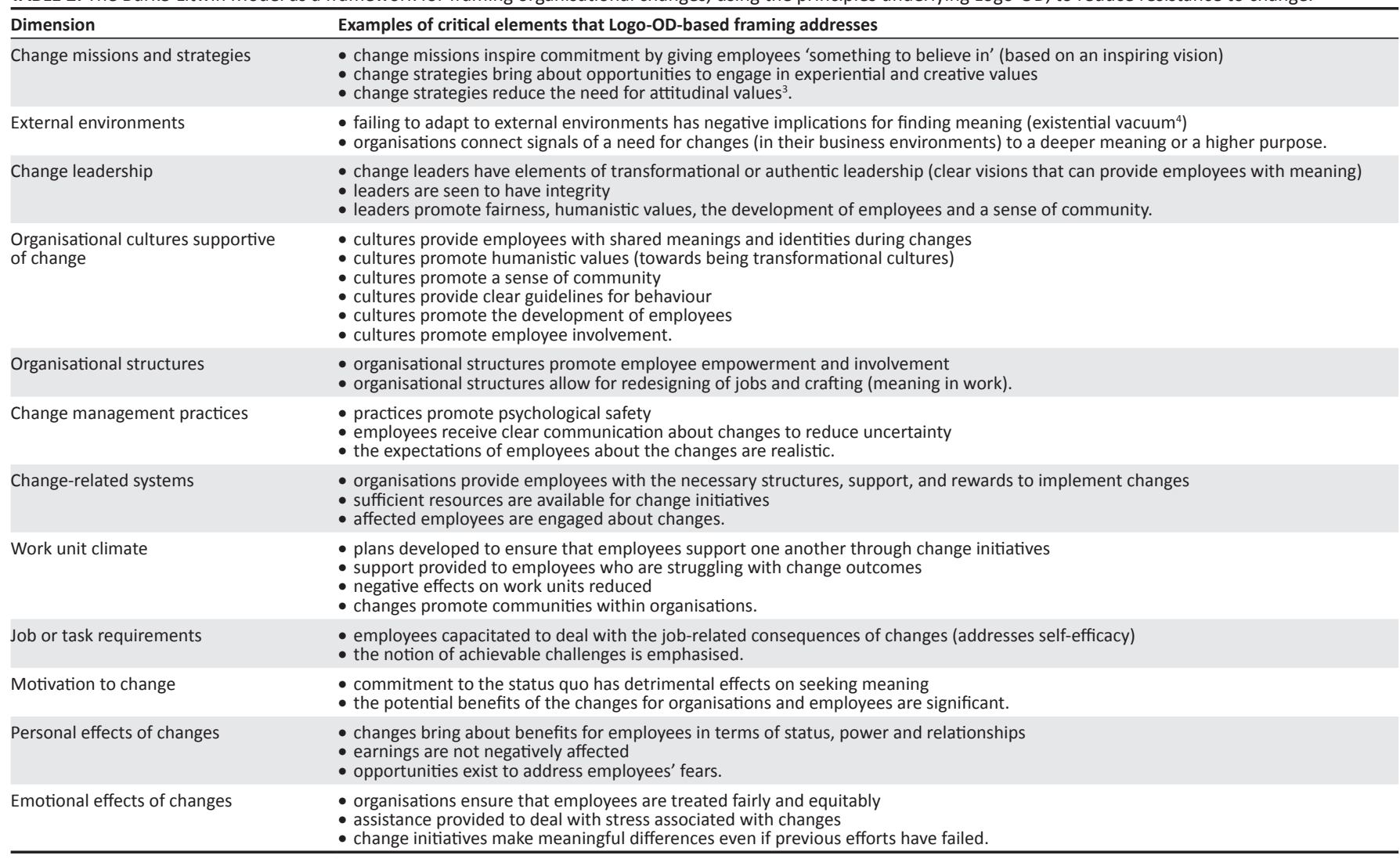

To meet the objectives of this article, the researchers presented their data in two sections. The first explored how organisations can create positive organisational contexts that will help employees to discover meaning. Here, the researchers presented the model of Pratt \& Ashforth (2003) as a framework for creating organisational practices that foster meaningfulness. This framework distinguishes between practices for increasing meaning in work, meaning at work and transcendence. They showed that each of the components of this model could play a substantial role in assisting employees to find meaning. This will ultimately facilitate the transcendence of employees' needs toward the needs of their organisations.

The second section of the literature review investigated the potential role of framing to help employees to find meaning during organisational changes. The researchers showed that there are two dominant perspectives about framing in the literature: the proponents of cognitive interpretation processes and those who focus on the role of language in creating meaning.

Subsequently, the researchers argued that, regardless of the perspective organisations follow, it might be beneficial for them to base framing on Logo-OD concepts because they will directly address what logotherapy regards as the central motivation in people's lives - to find meaning - and help to reduce resistance to change. They also showed that specific change frameworks, like the Burke-Litwin model, could also assist to focus framing interventions for optimal effectiveness. It is clear that one must take cognisance of the role of meaning and its implications for organisations when they implement change interventions practically: 'assisting individuals in finding meaning should not be interpreted as organisational altruism - it makes business sense' (Burger et al., 2008, p. 32).

However, Kizlik (2006) cautioned that organisations should not act in ways that will lead employees to believe that their interventions aim to change employees' attitudes to achieve greater gain for themselves. Isaksen (2000) warned that:

workers sense exploitation quickly and this leads to a negative perception of the working environment, which means a poor fit between person and environment and thus a lower sense of meaning in work. (p. 98)

Therefore, organisations should not see that the aim of the model the researchers developed in this article is to drive changes. In logotherapeutic terms, such a focus is hyperintention - a situation where a direct focus on a desirable state results in the state becoming unable to attain (Frankl, 1984). Instead, organisations must realise that changes in employees' attitudes will follow as a side effect of their finding meaning in the changing situation. The perceived integrity of the organisation and its leaders when they use Logo-OD and develop related interventions is critical.

By ensuring that employees can relate to a higher purpose in their organisations, thereby 'making, or being able to make, a difference in the world', they will become more 'positive about work' and more 'work motivated' (Schlechter \& Engelbrecht, 2006, pp. 3-4). Only when organisations achieve 
this state will they be able to achieve the objectives of the change initiative fully.

\section{Limitations of the study}

The main limitation of this study is that, after the findings of Burger et al. (2008) on the role of Logo-OD as positive trigger events for changes, there has been no empirical evidence to support the value of using meaning to facilitate organisational changes. Evidence that supports the findings of this article comes from studies that may not relate directly to its purpose - a limitation that is largely because of the use of the literature review and the relative novelty of the field of study. In addition, one may argue that conceptualising meaning using only the approach of the logotherapeutic school of thought limits the applicability of this construct.

\section{Future research opportunities}

The model the researchers presented for using meaning in change contexts provides a plethora of future research opportunities. Burger et al. (2008) have already established the relationship between meaning in life and resistance to change. Therefore, future research should focus on verifying the possible causal linkages between the various components of this model and employees' experiences of meaning empirically. In addition, developing instruments to measure meaning in or at work specifically, rather than investigating meaning in life in general, will be very useful (Burger, 2007).

\section{Conclusion}

The literature increasingly suggests the crucial role that employees' search for meaning could play in the success of organisational change initiatives. However, there has been no comprehensive model to date that provides organisations with a framework to use this knowledge best.

This article presented such a model, based on Logo-OD principles, together with an overview of how the model can assist employees to find meaning in their work contexts. The researchers recommend that researchers conduct further research to establish the usefulness of this model to facilitate organisational changes empirically.

\section{Acknowledgements Competing interests}

The authors declare that they have no financial or personal relationship(s) that may have inappropriately influenced them when they wrote this paper.

\section{Authors' contributions}

D.H.B. (University of Johannesburg), F.C. (University of Johannesburg) and G.R. (University of Johannesburg) all played critical roles in the conception and design of the research, the analysis and interpretation of data, and the drafting and revision of the article. Final approval of the version published was conducted by D.H.B. (University of Johannesburg).

\section{References}

Abel, C.F., \& Sementelli, A.J. (2005). Evolutionary critical theory, metaphor, and organizational change. Journal of Management Development, 24(5), 443-458. http://dx.doi.org/10.1108/02621710510598454

Alimo-Metcalfe, B., \& Alban-Metcalfe, J. (2006). More (good) leaders for the public sector. International Journal of Public Sector Management, 19(4), 293-315. http://dx.doi.org/10.1108/09513550610669167

Antonacopoulou, E.P., \& Gabriel, Y. (2001). Emotion, learning and organizational change: towards an integration of psychoanalytic and other perspectives. Journal of Organizational Change Management, 14(5), 435-451. http://dx.doi.org/10.1108/ EUM0000000005874

Armenakis, A.A., Harris, S.G., \& Mossholder, K.W. (1993). Creating readiness for organizational change. Human Relations, 46(6), 681-703. http://dx.doi. org/10.1177/001872679304600601

Atkinson, P. (2005). Managing resistance to change. Management Services, 49(1), 14-19.

Aust, P.J. (2004). Communicated values as indicators of organizational identity: a method for organizational assessment and its application in a case study. Communication Studies, 55(4), 515-534. http://dx.doi.org/10.1080/10510970409388636

Avolio, B.J., \& Luthans, F. (2006). The high impact leader: moments matter in accelerating authentic leadership development. New York: McGraw Hill.

Ayers, D.F. (2005). Organizational Climate in Its Semiotic Aspect: A Postmodern Community College undergoes renewal. Community College Review, 33(1), 1-22. http://dx.doi.org/10.1177/009155210503300101

Bartlett, C.A., \& Ghoshal, S. (1994). Changing the role of top management: beyond strategy to purpose. Harvard Business Review, 72(6), 79-88.

Bartlett, C.A., \& Ghoshal, S. (1995). Rebuilding behavioral context: turn process reengineering into people rejuvenation. Sloan Management Review, 37(1), 11-23.

Bartunek, J.M., Rousseau, D.M., Rudolph, J.W., \& DePalma, J.A. (2006). On the receiving end: sensemaking, emotion, and assessments of an organizational change initiated by others. The Journal of Applied Behavioral Science, 42(2), 182change initiated by others. The Journal of Applied Behav
206. http://dx.doi.org/10.1177/0021886305285455

Bass, B.M. (1985). Leadership and performance beyond expectations. New York: Free Press.

Bean, C.J., \& Hamilton, F.E. (2006). Leader framing and follower sensemaking: response to downsizing in the brave new workplace. Human Relations, 59(3), 321-349. http://dx.doi.org/10.1177/0018726706064177

Boerner, S., Eisenbeiss, S.A., \& Griesser, D. (2007). Follower behavior and organizational performance: the impact of transformational leaders. Journal of Leadership \& Organizational Studies, 13(3), 15-26. http://dx.doi.org/10.1177/1071791907013 0030201

Buhler, P.M. (2007). Developing the talent within. SuperVision, 68(5), 18-20.

Burger, D.H. (2007). The applicability of logotherapy as an organisation development intervention. Unpublished doctoral thesis, University of Johannesburg, Johannesburg South Africa.

Burger, D.H., \& Crous, F. (2002, September). An existential/humanistic perspective on strategy. Paper presented at the 8th Annual Psychological Society of South Africa (PsySSA) Conference, Cape Town.

Burger, D.H., Crous, F., \& Roodt, G. (2008). Logo-OD: The applicability of logotherapy as an OD intervention. South African Journal of Industrial Psychology, 34(1), 32-41.

Burnes, B. (2004). Emergent change and planned change - competitors or allies? The case of XYZ construction. International Journal of Operations \& Production Management, 24(9), 886-902. http://dx.doi.org/10.1108/01443570410552108

Byars, L.L., \& Rue, L.W. (2000). Human resource management. (6th edn.). Boston, MA: Irwin McGraw-Hill.

Cascio, W.F. (1998). Applied psychology in human resource management. (5th edn.). Upper Saddle River, NJ: Prentice Hall

Chawla, A., \& Kelloway, E.K. (2004). Predicting openness and commitment to change. Leadership \& Organization Development Journal, 25(6), 485-498. http://dx.doi. org/10.1108/01437730410556734

Chreim, S. (2006), Postscript to change: survivors' retrospective views of organizational changes Personnel Review, 35(3), 315-335. http://dx.doi. org/10.1108/00483480610656711

Collins, J.C., \& Porras, J.I. (1994). Built to last: successful habits of visionary companies. New York: Harper.

Cook, J., \& Crossman, A. (2004). Satisfaction with performance appraisal systems: a study of role perceptions. Journal of Managerial Psychology, 19(5), 526-541. http://dx.doi.org/10.1108/02683940410543605

Corley, K.G., Harquail, C.V., Pratt, M.G., Glynn, M.A., Fiol, C.M., \& Hatch, K.J. (2006). Guiding organizational identity through aged adolescence. Journal of Management Inquiry, 15(2), 85-99. http://dx.doi.org/10.1177/1056492605285930

Csikszentmihalyi, M. (2003). Good business: leadership, flow, and the making of meaning. New York: Penguin.

Cummings, T.G., \& Worley, C.G. (2001). Organization development and change (7th edn.). Cincinnati, OH: South-Western College.

Das, A.K. (1998). Frankl and the realm of meaning. Journal of Humanistic Counseling Education and Development, 36(4), 199-212. 
Davidson, E. (2006). A technological frames perspective on information technology and organizational change. The Journal of Applied Behavioral Science, 42(1), 23-39. http://dx.doi.org/10.1177/0021886305285126

Dolan, S.L., \& Garcia, S. (2002). Managing by values: cultural redesign for strategic organizational change at the dawn of the twenty-first century. Journal of Management Development, 21(2), 101-117. http://dx.doi. org/10.1108/02621710210417411

Drucker, P.F. (2002). They're not employees, they're people. Harvard Business Review, 80(2), 70-77.

Fabry, J.B. (1987). The pursuit of meaning: Viktor Frankl, logotherapy, and life. (revised edn.). Berkeley, CA: Institute of Logotherapy Press.

Fabry, J.B. (1988). Guideposts to meaning: discovering what really matters. Berkeley, CA: Institute of Logotherapy Press.

Folger, R., \& Skarlicki, D.P. (1999). Unfairness and resistance to change: hardship as mistreatment. Journal of Organizational Change Management, 12(1), 35-50. http://dx.doi.org/10.1108/09534819910255306

Fornaciari, C.J., \& Dean, K.L. (2002). Making the quantum leap: Lessons from physics on studying spirituality and religion in organizations. Journal of Organizational Change Management, 14(4), 335-351. http://dx.doi.org/10.1108/

Frances, M. (1995). Organizational change and personal mythology. Personnel Review, 24(4), 58-68. http://dx.doi.org/10.1108/00483489510091783

Frankl, V.E. (1967). Psychotherapy and existentialism: selected papers on logotherapy. New York: Washington Square Press.

Frankl, V.E. (1978). The unheard cry for meaning: psychotherapy and humanism. New York: Washington Square Press.

Frankl, V.E. (1984). Man's search for meaning (revised edn.). New York: Washington Square Press.

Frankl, V.E. (1986). The doctor and the soul: from psychotherapy to logotherapy. (3rd edn.). New York: Random House.

Frankl, V.E. (1988). The will to meaning: foundations and applications of logotherapy. (2nd edn.). New York: Meridian.

Frankl, V.E. (2000a). Man's search for ultimate meaning. Cambridge, MA: Perseus.

Frankl, V.E. (2000b). Recollections: an autobiography (transl., J. Fabry \& J. Fabry). Cambridge, MA: Perseus.

French, W.L., \& Bell, C.H., Jr. (1999). Organization development: behavioral science interventions for organization improvement. (6th edn.). Upper Saddle River, NJ: Prentice Hall.

Gardner, H. (2004). Changing Minds. Boston, MA: Harvard Business School Press.

Gostick, A., \& Telford, D. (2006). The integrity advantage. Canadian HR Reporter, 19(22), 35.

Gratton, L. (1998). The new rules of HR strategy. HR Focus, 75(6), 13-14.

Gratton, L. (2000). Living strategy: putting people at the heart of corporate business. London: Prentice Hall.

Green, D.D. (2007). Leading a postmodern workforce. Academy of Strategic Management Journal, 6, 15-26.

Greenstein, M., \& Breitbart, W. (2000). Cancer and the experience of meaning: a group psychotherapy for people with cancer. American Journal of Psychotherapy, 54(4), 486-500.

Hackman, J.R., \& Oldham, G.R. (1980). Work redesign. Reading, MA: Addison-Wesley

Haralambos, M., \& Holborn, M. (1995). Sociology: themes and perspectives. (4th edn.). London: Collins Educational.

Hart, C. (2005). Doing a Literature Review. (5th edn.). London: SAGE.

Havenga Coetzer, P. (1997). Viktor Frankl the man. In F. Crous, A.A. Havenga Coetzer \& G. Van den Heever (Eds.), On the way to meaning: essays in remembrance of Viktor Frankl (pp. 11-19). Benmore: Viktor Frankl Foundation of South Africa.

Heil, G., Bennis, W., \& Stephens, D.C. (2000). Douglas McGregor, revisited: managing the human side of the enterprise. New York: John Wiley.

Hopkins, M.M., O'Neil, D.A., \& Bilimoria, D. (2006). Effective leadership and successful career advancement: perspectives from women in health care. Equal Opportunities International, 25(4), 251-271. http://dx.doi. org/10.1108/02610150610706249

Isaksen, J. (2000). Constructing meaning despite the drudgery of repetitive work. Journal of Humanistic Psychology, 40(3), 84-107. http://dx.doi. org/10.1177/0022167800403008

Jackson, S.E., \& Schuler, R.S. (1999). Understanding human resource management in the context of organizations and their environments. In R.S. Schuler \& S.E. Jackson (Eds.), Strategic human resource management (pp. 4-28). Malden, MA: Blackwell.

Kets de Vries, M.F.R. (2001). The leadership mystique: a users manual for the human enterprise. London: Prentice Hall.

Kinnear, C., \& Roodt, G. (1998). The development of an instrument to measure organisational inertia. South African Journal of Industrial Psychology, 24(2), 44-54.

Kizlik, L. (2006). Coping with change. Multichannel Merchant, 23(10), 42-46.

Kurashina, Y. (2005). Peacekeeping participation and identity changes In the Japan selfdefense forces: military service as 'dirty work'. Unpublished doctoral dissertation, defense forces: military service as dirty
University of Maryland, College Park.

Lewin, K. (1951). Field theory in social science. New York: Harper \& Row.
Luthans, F., \& Avolio, B. (2003). Authentic leadership development. In K.S. Cameron J.E. Dutton \& R.E. Quinn (Eds.), Positive organizational scholarship: foundations of a new discipline (pp. 241-258). San Francisco, CA: Berret Koehler.

Markow, F., \& Klenke, K. (2005). The effects of personal meaning and calling on organizational commitment: an empirical investigation of spiritual leadership. The International Journal of Organizational Analysis, 13(1), 8-27. http://dx.doi. org/10.1108/eb028995

McGregor, D. (1960). The human side of enterprise. New York: McGraw-Hill.

Milliman, J., Ferguson, J., Trickett, D., \& Condemi, B. (1999). Spirit and community at Southwest Airlines: an investigation of a spiritual values-based model. Journal of Organizational Change Management, 12(3), 221-233. http://dx.doi. org/10.1108/09534819910273928

Morin, E.M. (1995). Organizational effectiveness and the meaning of work. In T.C. Pauchant \& Associates (Eds.), In search of meaning: managing for the health of our organizations, our communities, and the natural world (pp. 29-64). San of our organizations,
Francisco: Jossey-Bass.

Newstrom, J.W. \& Davis, K. (1997). Organizational behavior: human behavior at work. (10th edn.). New York. McGraw Hill.

O'Reilly, C.A., \& Pfeffer, J. (2000). Hidden value: how great companies achieve extraordinary results with ordinary people. Boston, MA: Harvard Business School Press.

Perez, J.R., \& De Pablos, P.O. (2003). Knowledge management and organizational competitiveness: a framework for human capital analysis. Journal of Knowledge Management, 7(3), 82-91. http://dx.doi.org/10.1108/13673270310485640

Peters, T.J., \& Waterman, R.H. (1982). In search of excellence. New York: Warner.

Prahalad, C.K., \& Hamel, G. (1990). The core competencies of the corporation. Harvard Business Review, 68, 79-91.

Pratt, A., \& Ashforth, B.E. (2003). Fostering meaningfulness in working and at work. In K.S. Cameron, J.E. Dutton \& R.E. Quinn (Eds.), Positive organizational scholarship: foundations of a new discipline (pp. 309-327). San Francisco, CA: Barrett Koehler.

Richardson, H.A., \& Vandenberg, R.J. (2005). Integrating managerial perceptions and transformational leadership into a work-unit level model of employee involvement. Journal of Organizational Behavior, 26, 561-589. http://dx.doi. org/10.1002/job.329

Rosenthal, P., \& Peccei, R. (2006). The customer concept in welfare administration front-line views in Jobcentre Plus. The International Journal of Public Sector Management, 19(1), 67-78. http://dx.doi.org/10.1108/09513550610640401

Saunders, M., Lewis, P., \& Thornhill, A. (2007). Research Methods for Business Student. (4th edn.). UK: Pearson Education Ltd, UK.

Schein, E.H. (1994). Organizational psychology. (3rd edn.). Upper Saddle River, NJ: Prentice Hall.

Schein, E.H. (1996). Kurt Lewin's change theory in the field and in the classroom: notes toward a model of managed learning. Systems Practice, 9(1), 55-70. http://dx.doi org/10.1007/BF02173417

Schlechter, A.F., \& Engelbrecht, A.S. (2006). The relationship between transformational leadership, meaning and organizational citizenship behaviour. Management Dynamics, 15(4), 2-16.

Schuler, R.S., \& Jackson, S.E. (Eds.). (1999). Strategic human resource management. Oxford: Blackwell Business.

Schuler, R.S., Jackson, S.E., \& Storey, J. (2001). HRM and its link with strategic management. In J. Storey (Ed.), Human resource management: a critical text. ( $2 \mathrm{nd}$ edn., pp. 114-130). London: International Thompson Learning.

Scroggins, W.A. (2006). Managing meaning for strategic change: the role of perception and meaning congruence. Journal of Health and Human Services Administration 29(1/2), 83-103.

Shantall, T. (1989). Viktor Frankl's existential theory. In W.F. Meyer, C. Moore \& H.G. Viljoen (Eds.), Personality theories - from Freud to Frankl (pp. 421-439). Johannesburg: Lexicon.

Smith, I. (2005a). Achieving readiness for organisational change. Library Management 26(6/7), 408-412. http://dx.doi.org/10.1108/01435120510623764

Smith, I. (2005b). Continuing professional development and workplace learning 11: Managing the "people" side of organisational change. Library Management, 26(3), 152-155. http://dx.doi.org/10.1108/01435120510580898

Strandgaard Pedersen, J., \& Dobbin, F. (2006). In Search of identity and legitimation bridging organizational culture and Neoinstitutionalism. The American Behavioral Scientist, 49(7), 897-907. http://dx.doi.org/10.1177/0002764205284798

Towers Perrin Global Workforce Study (2005). Ten steps to creating an engaged workforce: key European findings. Brussels: Towers Perrin HR Services.

Varoglu, D., \& Eser, Z. (2006). How service employees can be treated as internal customers in hospitality industry. The Business Review, Cambridge, 5(2), 30-35.

Warren, R.C. (1996). The empty company: morality and job security. Personnel Review, 25(6), 41-53. http://dx.doi.org/10.1108/00483489610148527

Washburn, E.R. (1998). The physician leader as logotherapist. Physician Executive, 24(4), 34-39.

Wrzesniewski, A. (2003). Finding positive meaning in work. In K.S. Cameron, J.E. Dutton \& R.E. Quinn (Eds.), Positive organizational scholarship: foundations of a new discipline (pp. 296-308). San Francisco, CA: Barrett Koehler.

Xenikou, A., \& Simosi, M. (2006). Organizational culture and transformational leadership as predictors of business unit performance. Journal of Managerial Psychology, 21(6), 566-579. http://dx.doi.org/10.1108/02683940610684409

Yun, S., Cox, J., \& Sims, J.P., Jr. (2006). The forgotten follower: a contingency model of leadership and follower self-leadership. Journal of Managerial Psychology, 21(4), 374-388. http://dx.doi.org/10.1108/02683940610663141 